\title{
A NEW EUROPEAN HIGH FIDELITY SOLAR ARRAY SIMULATOR FOR NEAR EARTH AND DEEP SPACE APPLICATIONS Hjalti Pall Thorvardarson ${ }^{(1)}$, Flemming Gottsche ${ }^{(2)}$, Ferdinando Tonicello ${ }^{(3)}$ \\ (1) Rovsing, Dyregaardsvej 2 DK-2740 Skovlunde Denmark,Email:hpt@rovsing.dk \\ (2) Rovsing, Dyregaardsvej 2 DK-2740 Skovlunde Denmark,Email:fgo@rovsing.dk \\ (3) ESA-ESTEC, Keplerlaan 1, 2200AG Noordwijk, The Netherlands, Email: Ferdinando.tonicello@esa.int
}

\begin{abstract}
Following an intensive design, development, and testing effort of almost 3 years, Rovsing with ESA assistance succeeded in the development of a new European high fidelity Solar Array Simulator (SAS) for near Earth and deep space applications. ESA now has a versatile, highly modular and efficient SAS at its disposition that serves at simulating modern high power solar arrays for Earth observation, science or telecom satellites as well as for future deep space missions.
\end{abstract}

The special features compared to other SAS are:

- Ultra-fast dynamic response performance, the key to high fidelity to SA simulation within the space domain.

- $\quad$ I-V curves can be simulated with up to 4096 point resolution.

- Store $600 \mathrm{I} / \mathrm{V}$ curves in memory and create full life cycle simulations.

- $\quad \mathrm{Up}$ to $685 \mathrm{~W}$ of Power from a single module (137V / 5A \& 68.5V / 10A).

- Class leading energy efficiency from a hybrid design, translating into less heat dissipation and therefore considerable less noise from the SAS rack as a whole.

- The smallest form factor available, $2740 \mathrm{~W}$ from a single $3 \mathrm{U}$ high unit, with no need for additional forced cooling devices or empty space sections between stacked sub-racks.

- Programmable first level protection (OVP, OCP).

Since the beginning of 2016 ESA is able to prepare its demanding missions with a flexible and leading edge SAS solution. The SAS is already foreseen to support missions like JUICE, MetOp-SG, ExoMars and the MPCV European Service Module.

The paper describes the development logic, challenges and lessons learned as well as the successfully concluded qualification testing phase of the new SAS and gives an outlook on future applications and features that are soon to be added.

\section{ROVSING PROFILE AND ORGANIZATION}

Rovsing was established in 1992 and has been listed on the OMX Nordic Stock exchange since December 2006.
Rovsing is located in Skovlunde on the outskirts of Copenhagen, Denmark. Website: www.rovsing.dk.

Rovsing is recognised for the delivery of ground testing equipment and systems, software solutions and consultancy services to the European Space Agency (ESA), European space prime contractors and U.S. defence primes and has achievements within the following business areas:

- Test systems for electrical and functional testing of complex and hybrid electronic and software systems, in particular for satellite subsystems, several of them being best in class.

- Critical and non-critical software systems.

- Independent software verification and validation (ISVV) services.

- Software process assessment and improvement services.

- $\quad$ Engineering and logistics support.

\subsection{History of the Development}

Initial work started within Rovsing in 2009 with the idea about creating a European Solar Array Simulator based on in-house differentiating topology. Rovsing approached ESA and Danish High Technology Fond for seeking backing in the development.

Rovsing and ESA kicked off phase 1 of the SAS development in December 2009. Phase 1 covered the definition of the requirements, proof of concept, and was concluded in October 2011:

- Task 1: SAS requirements and specification

- Task 2: SAS preliminary design

- Task 3: SAS power module board - breadboard implementation

- $\quad$ Task 4: SAS power module board - breadboard testing

- Task 5: Commercial evaluation

Phase 2 covered the maturing of the requirements and the design into a SAS product:

- Task 1: Consolidation of system requirements and design

- $\quad$ Task 2: Prototyping

- Task 3: Prototypes Control Implementation and Integration 
- $\quad$ Task 4: SAS prototypes integrated test

- Task 5: manufacturing and individual test of 10 SAS series-0 modules

- Task 6: Final System Test, Validation and Documentation

\section{WHAT IS A SOLAR ARRAY SIMULATOR}

\subsection{Solar Cell Characteristics}

A SAS must emulate the electrical characteristics of an array of solar cells as precisely as possible. A common multi junction solar cell model is shown in Fig 1.

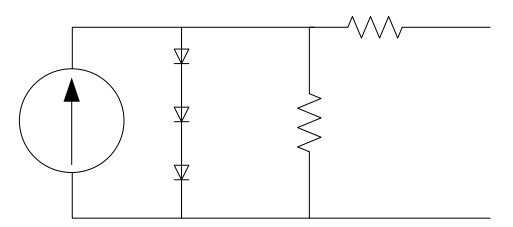

Figure 1: Triple junction solar cell equivalent.

On spacecrafts, solar cells connected in series form a string; multiple strings connected in parallel are denominated a "section", see Figure 2.

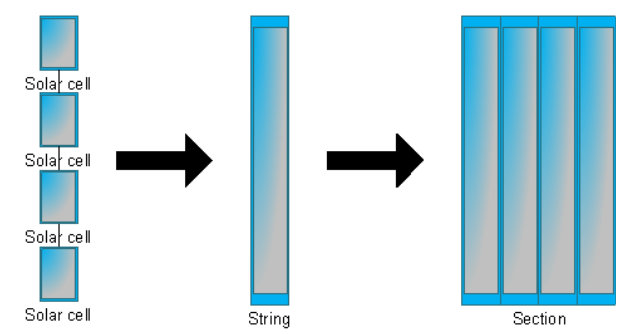

Figure 2: Solar cell connections

One SAS Module output must emulate such a section. A spacecraft solar array (SA) consists of multiple sections; hence multiple SAS Modules are required to emulate the array.

The power from a solar array is expressed as follows:

$$
\mathrm{P}=\mathrm{I}^{*} \mathrm{~V}
$$

The I/V curve of a given SA section is a function of the:

- Illumination

- Temperature

- $\quad$ SA technology used

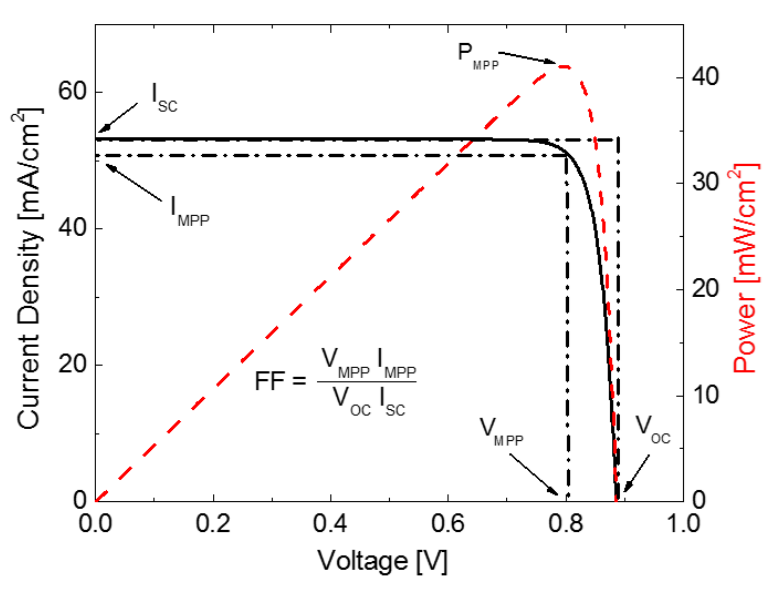

Figure 3: Solar cell characteristic (single junction)

An I/V curve is characterized by the following parameters (see Figure 3): Open circuit voltage (Voc), Short circuit current (Isc), Voltage level at the maximum power point (Vmp), Current level at the maximum power point (Imp), Maximum power point (Pmpp), Fill Factor (FF)

These I/V characteristics are what the SAS must emulate. Hence, the SAS Module must always control the current to achieve an operation point on the curve. Dynamic behaviour of the solar cell section must furthermore also be emulated as close as possible.

[Britton] presents an equation that gives a good representation of the relation between voltage and current based on the above parameters of the string:

$$
V=\frac{\frac{V_{O C} \ln \left(2-\left(\frac{I}{I_{S C}}\right)^{N}\right)}{\ln (2)}-R_{S}\left(I-I_{S C}\right)}{1+\frac{R_{S} I_{S C}}{V_{O C}}}
$$

where

$$
\begin{gathered}
N=\frac{\ln \left(2-2^{a}\right)}{\ln \left(\frac{I_{M P}}{I_{S C}}\right)}(2) \\
a=\frac{V_{M P}\left(1+\frac{R_{S} I_{S C}}{V_{O C}}\right)+R_{S}\left(I_{M P}-I_{S C}\right)}{V_{O C}} \\
R_{S}=\frac{V_{O C}-V_{M P}}{I_{M P}}(4)
\end{gathered}
$$

For now, the [Britton] equations are considered to be the most accurate way to simulate the behaviour of triple junction GaAs cells and are used in the remaining part of this document to supply I/V behaviour.

\subsection{Dynamic Performance and Response Time}

An overall goal for a SAS is to simulate the 
performance of real solar cells as close as possible, both statically (voltage and current levels) and also the dynamic behaviour with respect to output capacitance, response time, etc. Therefore the response time of the SAS Module output has been identified as one of the most important design drivers.

It can be useful to look at where the SAS Module is operating on an I/V curve when specifying the dynamic behaviour. Figure 4 defines three areas of the I/V curve; different types of power conditioning units normally work within only one of the three areas when steady state is reached. Systems based on shunt regulators can behave in a way that covers "Case 2" and "Case 3" when the operating point of one section jumps from Isc to MPP.

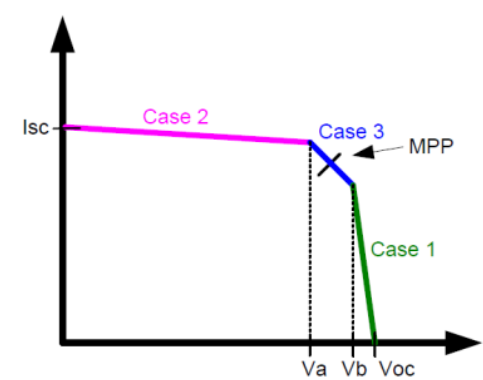

Figure 4: Working areas of the I/V curve.

Examples of regulators working in the 3 areas are:

- Series switching devices or DC-DC converters operating in the area of "Case 1".

- Shunt regulators in the area of "Case 2". Also in "Case 3" when operating point of a section jumps from Isc to MPP.

- Maximum power point trackers in the area of "Case 3".

It is in this perspective the requirements of recovery from short- and open-circuit and requirements of response time below $10 \mu \mathrm{s}$ strain the designs of both the overall digital control and the power stage of the SAS Module. Research and detailed design has been the major results of the proof-of-concept activity.

\section{RO-5100 SAS MODULE OVERVIEW}

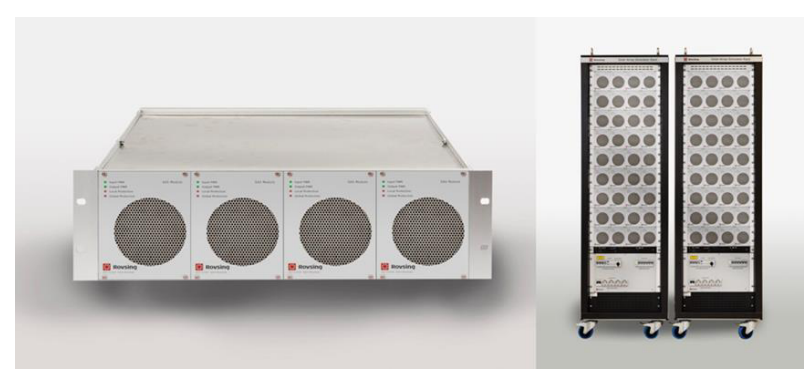

Figure 5: RO-5100 SAS Modules

The Rovsing RO-5000 SAS product range provides the following primary advantages to space customers:

- Ultra-fast dynamic response performance, the key to high fidelity to SA simulation within the space domain.

- Up to $685 \mathrm{~W}$ of Power from a single module (137V / 5A \& 68.5V / 10A).

- Class leading energy efficiency from a smart linear + switch-mode power hybrid design, translating into less heat dissipation and therefore considerable less noise from the SAS rack as a whole.

- Excellent static and dynamic performance

- Low ripple and noise

- Fast load switch recovery time

- Up to $600 \mathrm{I} / \mathrm{V}$ tables with each 4096 point resolution

- Voc, Isc, Imp and Vmp

- Highly configurable Curve switching

- $100 \mathrm{~ms}$ to 9 hours

- High accuracy for measurement, programming and read-back

- Programmable First Level Protection

- Over Voltage Protection (OVP), Over Current Protection (OCP) and Over Temperature Protection (OTP)

- Excellent thermal management

- Low heat dissipation

- Low noise

- High MTBF

- FMECA - Functional Level

- Control and monitoring through Ethernet

- SCPI interface

- The smallest form factor available, $2740 \mathrm{~W}$ from a single $3 \mathrm{U}$ high unit, with no need for additional forced cooling devices or empty space sections between stacked sub-racks.

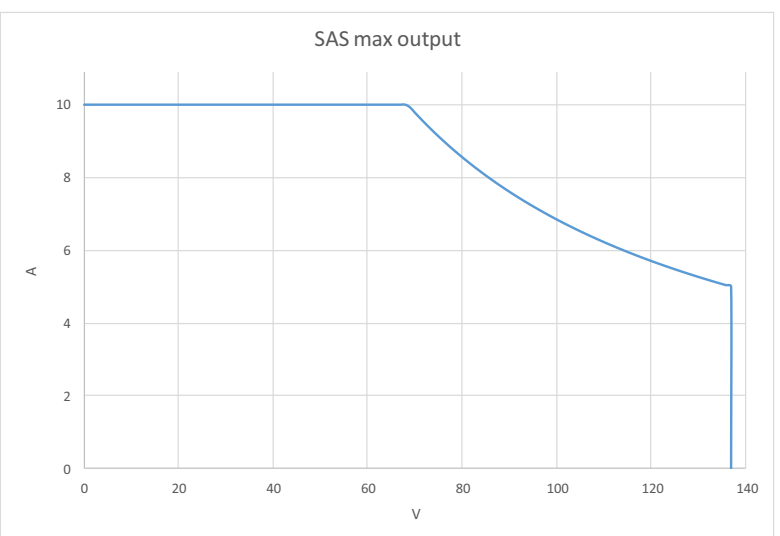

Figure 6: RO-5100 SAS Module Power Profile

The standard SAS Module (RO-5100) provides output voltage up to $137 \mathrm{~V}$ covering the full range of spacecraft needs, with custom RO-510x variants available on request for higher voltage levels. The RO-5100 provides high programming accuracy; curves can be simulated with up to 4096 point resolution with up to $600 \mathrm{I} / \mathrm{V}$ 
curves stored in memory, with switching between curves programmed from $100 \mathrm{~ms}$ up to approximately 9 hours. The unit provides excellent ripple and noise performance, load switch recovery time of less than 10us and outstanding measurement accuracy. A high fidelity simulation of the actual solar array is provided both statically (voltage and current levels) and also in terms of dynamic behavior with respect to output capacitance and response time. The RO-5100 provides excellent static and dynamic performance across the principle regulation types (series switching, shunt regulation and MPPT), providing the user with the high fidelity required to accurately simulate the behavior of the actual solar throughout its lifecycle.

Each RO-5100 SAS Module is fully self-contained with regards to inputs, outputs and its chassis thus easing configurability and management as units can be slid in and out of the rack without the need for adjusting the rest of the system.

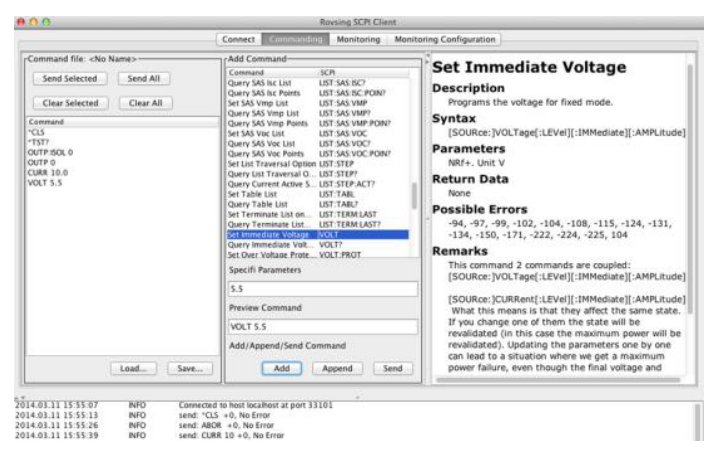

\subsection{SAS System Overview}

A Rovsing Solar Array Simulator System could consist of:

- SAS Modules that supply power to the spacecraft (S/C) simulating the electrical characteristics of the $\mathrm{S} / \mathrm{C}$ solar array (or sections thereof).

- 19" Rack, SAS Subracks, isolation transformer

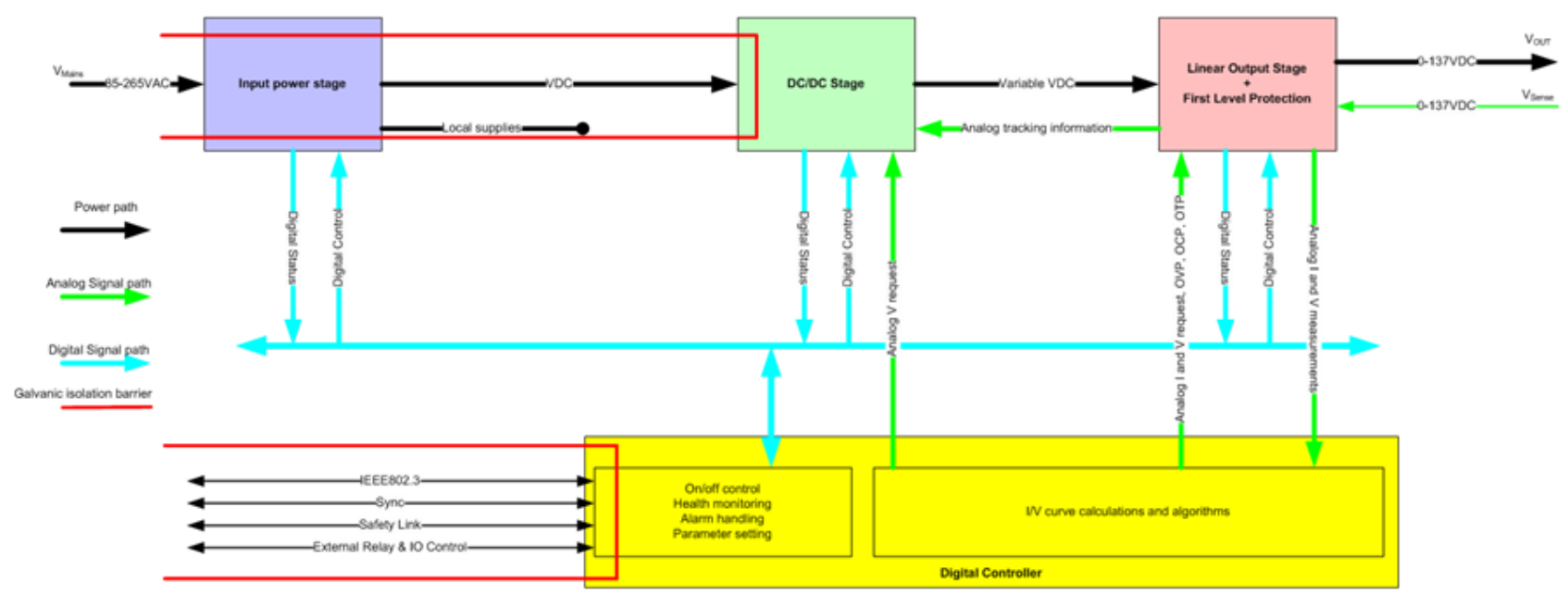

Figure 7: SAS Block Diagram

The unit is designed for high density rack integration achieved via its small size and low power dissipation. Due to this design, the unit possesses no input buttons or keypads at the front, only basic LED indicators. The saved space is utilized by the cooling fan partly responsible for achieving the high density of a $3 \mathrm{U}$ high sub rack, housing up to $4 x$ SAS Module. Since the unit does not present a keypad input or an LCD output to the end user, all of its commanding and monitoring is performed remotely through the SCPI interface via standard Ethernet. Hence all SAS Modules are delivered with the standalone "SCPI Client", a simple lightweight JAVA based tool with the following features:

- Connect and configure

- Commanding

- Monitoring

- Full API overview

- Simple scripting for mains input, harness, Ethernet switches and other support equipment such as Second Level Protection (SLP) Modules.

- Controller PC hosting the SAS Module/s Client Software and Control Software, where the operator through a GUI can:

- Use the Scenario Editor to create scenarios simulating events such as course of a day, spinning of the $\mathrm{S} / \mathrm{C}$, and eclipse events. During execution of a scenario, the SAS Module/s is continuously re-configured according to a time-line.

- Manually configure the SAS Module/s to simulate specific solar array configurations (the configuration reflects a given type of solar cell, insolation, and temperature).

- Receive status from the SAS Module/s.

The figure below shows a possible SAS System and its contents. Depending on number of SAS Modules, there 
can be several racks for the individual project.

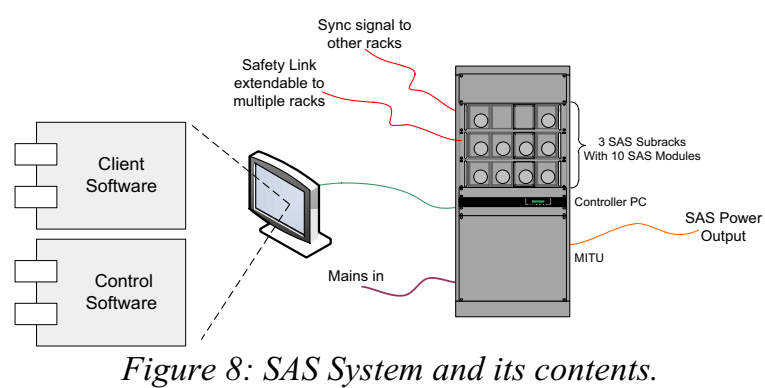

The following design decisions were made during initial studies and are therefore requirements for the SAS Product Development:

- Each SAS Subrack must hold up to 4 SAS Modules (plugged-in from the front), all cabling being handled on the back. The SAS Modules operate in a stand-alone fashion, i.e. no resources are shared between the SAS Modules. All control and TM communication is handled via Ethernet interfaces.

- The Sync signal shown in Figure 8 is used to synchronise all SAS Modules connected together when they are programmed to switch between two or more different output characteristics (to simulate the changes in solar cell output characteristics when the illumination or temperature changes, or in case of a defective solar cell section or similar). If multiple racks are present in the SAS, the sync signal must be distributed to these also. The Sync signal master is determined by cable select.

- Safety Link is supported by the SAS Module/s. Safety Link is a concept developed by Rovsing where a safety event can trigger the link causing all connected equipment to power down the output. When the SAS Modules are used in combination with Rovsing's Second Level Protection (or SLP) then a triggering of the Safety Link will instantly galvanically isolate the output towards the S/C. The Safety Link can be extended between multiple SAS Modules and when combined with the Rovsing Measurement Acquisition Simulation Commanding (MASC) it can also be connected to various types of COTS equipment.

\subsection{SAS Client Software}

The objective of the Scenario Editor is to provide the operator with the ability to create complex scenarios with relative ease, and in the process make sure the user retains a full overview. Figure 9 shows the major components of Scenario App Software.

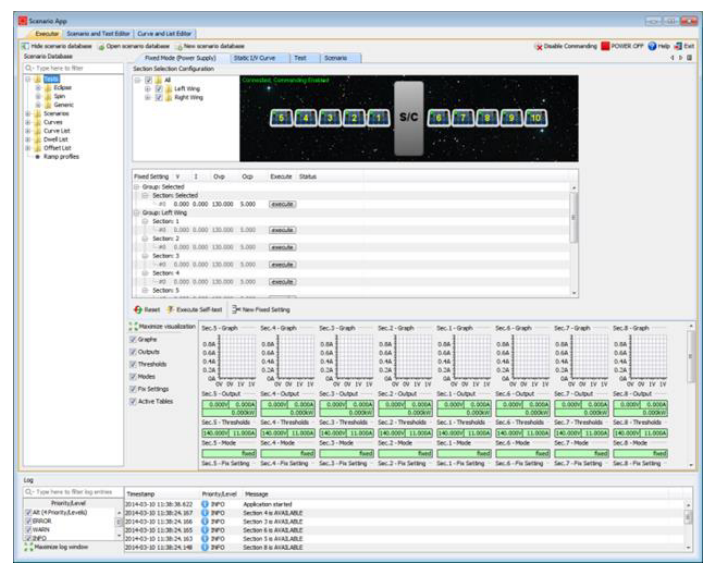

Figure 9: Scenario App Software.

\section{- Scenario Editor}

- The Scenario Editor can create, load, modify, rename, save and delete objects in the Scenario Database. Eclipse events and other custom curve progressions can be programmed in the editor.

\section{- Scenario Executor}

- The Scenario Executor can send Scenario Databases for preparation in the Scenario Backend, and it can issue execution start, hold, resume and stop commands to the Scenario Backend.

- Curve Editor

- The Curve Editor can be used to create, load, modify, rename, save and delete IV Curve Formulas and IV Curve Tables.

- Main

- The Main Object is the Scenario App framework which ties components of the Scenario App together.

- Scenario Database

- A Scenario Database is a mapping of identifiers to Scenario Database Objects and the Scenario Database Objects. The Scenario Database objects are Scenarios, Tests, Groups, Sections, $\{\mathrm{I}, \mathrm{V}\}$ Curve Formulas, $\{\mathrm{I}, \mathrm{V}\}$ Curve Formula sequences, $\{\mathrm{I}, \mathrm{V}\}$ Curve Tables Sequences, $\{\mathrm{I}, \mathrm{V}\}$ Curve Tables, Offset Graphs and SAS Modules.

\section{- Communication}

- The Communication Object handles communication between the Scenario App and the Control App. 


\section{KEY TEST RESULTS}

For the key performance parameters and use cases the following sections show the applied test setups and the test results achieved with the RO-5100 SAS Module. In all screen-shots, yellow trace is Voltage and red is Current.

\section{Shunt Switching Testing:}

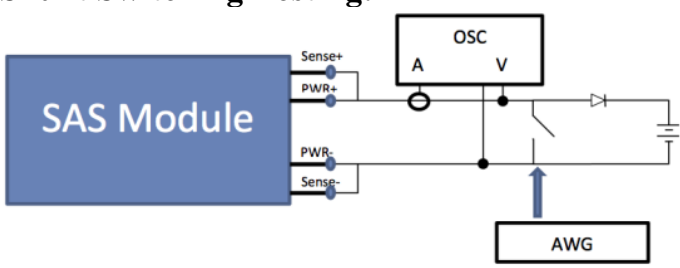

Battery emulator is configured to the desired open circuit battery voltage (by means of power supply) and current sinking capability (by means of fixed resistive load).

S3R emulator includes a heavy duty MOSFET controlled by an arbitrary waveform generator (AWG).

Example of actual performance in shunt switching, configuration shown in title:

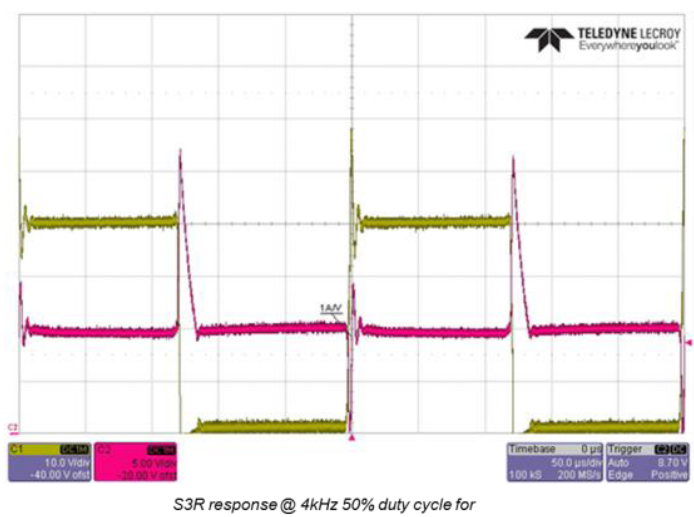

W curve VOC $=65 \mathrm{~V}, I S C=10 \mathrm{~A}, V M P=46 \mathrm{~V}, I M P=9.2 \mathrm{~A}$ with $40 \mathrm{~V}$ battery

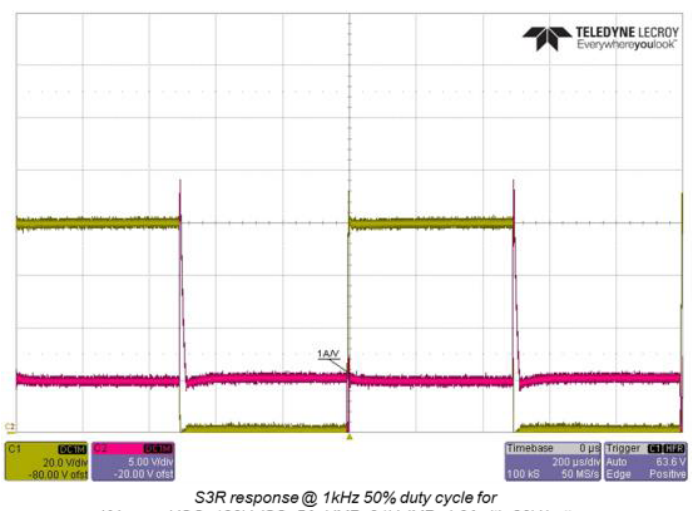

S3R response $@ 1 \mathrm{kHz} 50 \%$ duty cycle for
$W$ curve VOC=130V, ISC $=5 A, V M P=91 \mathrm{~V}, I M P=4.6$ Awith $80 \mathrm{~V}$ battery

\section{Series Switching Testing:}

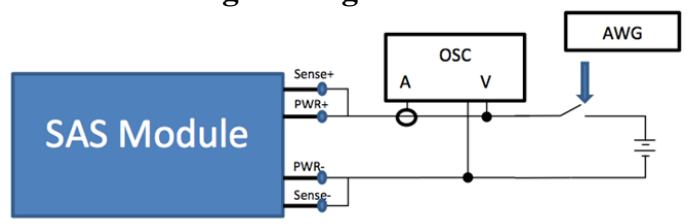

The output is switched by a P-channel MOSFET driven by an OP-Amp with $200 \mathrm{~V}$ common mode range, connected to the positive output of the SAS Module.

Example of actual performance in series switching, configuration shown in title:

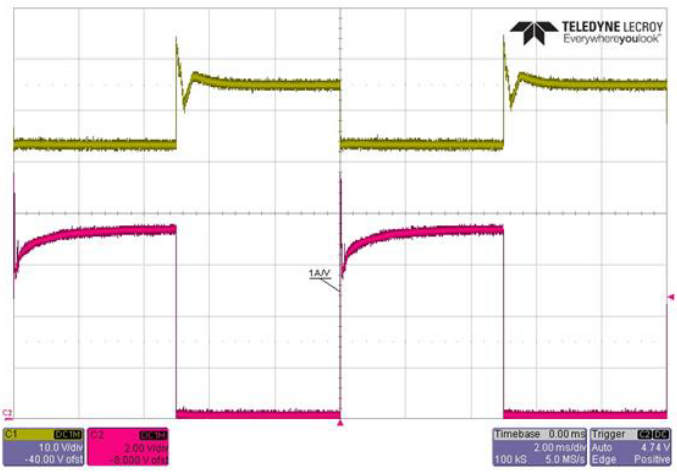

Series switching response @ $100 \mathrm{~Hz} 50 \%$ duty cycle for $\mathrm{I} / \mathrm{V}$ curve $\mathrm{VOC}=65 \mathrm{~V}$, ISC $=10 \mathrm{~A}, \mathrm{VMP}=46 \mathrm{~V}$, IMP $=9.2 \mathrm{~A}$ with $53 \mathrm{~V}$ battery

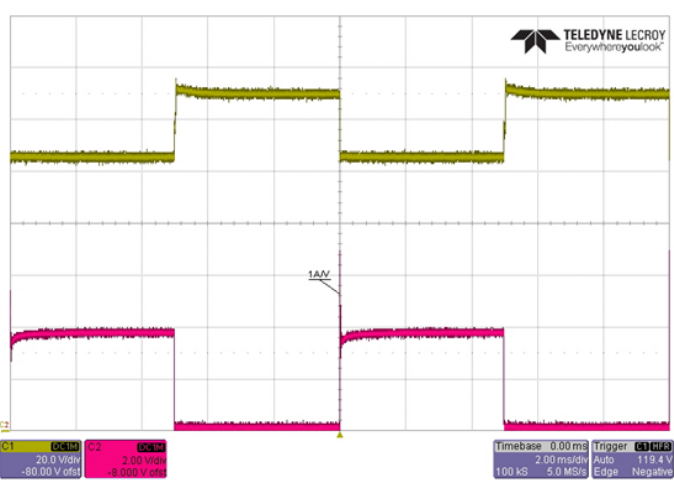

Series switching response @ $100 \mathrm{~Hz} 50 \%$ duty cycle for $\mathrm{I} / \mathrm{V}$ curve $\mathrm{VOC}=130 \mathrm{~V}, \mathrm{ISC}=5 \mathrm{~A}, \mathrm{VMP}=91 \mathrm{~V}, \mathrm{IMP}=4.6 \mathrm{~A}$ with $106 \mathrm{~V}$ battery.

\section{MPPT Testing:}

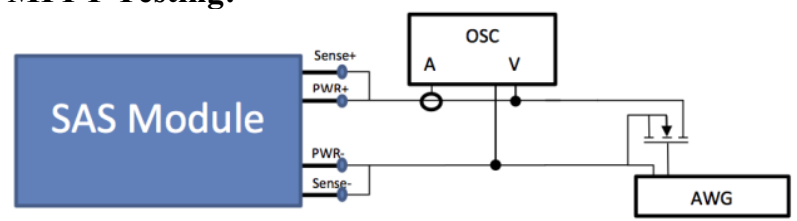

Electronic load is sweeping repeatedly between Vmin and Vmax triangular wave shape $50 \%$ duty cycle at noted frequency. (I.e. $\mathrm{dV} / \mathrm{dt}=(\mathrm{Vmax}-\mathrm{Vmin}) * 2 *$ freq $)$.

Example of actual performance during MPPT, configuration shown in title: 

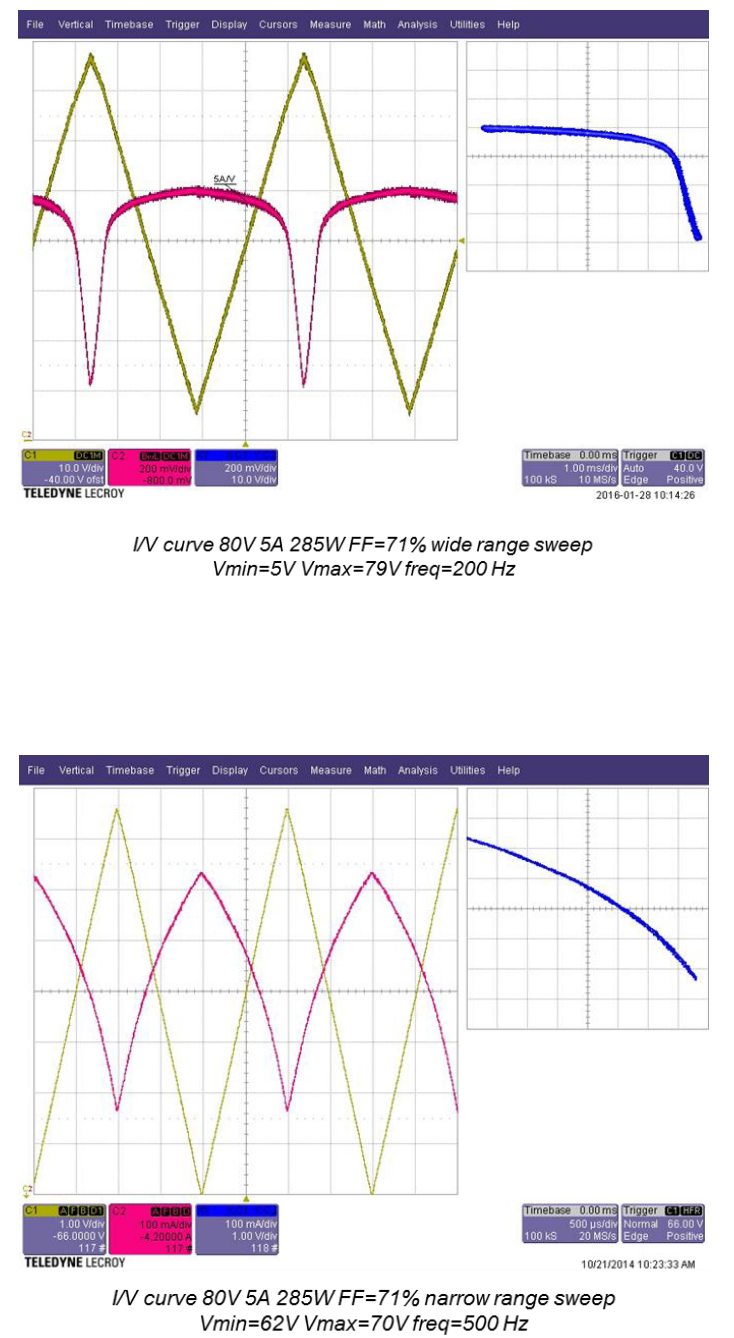

\section{Output Noise Testing:}

Example of actual noise performance, with output ON and external loading:

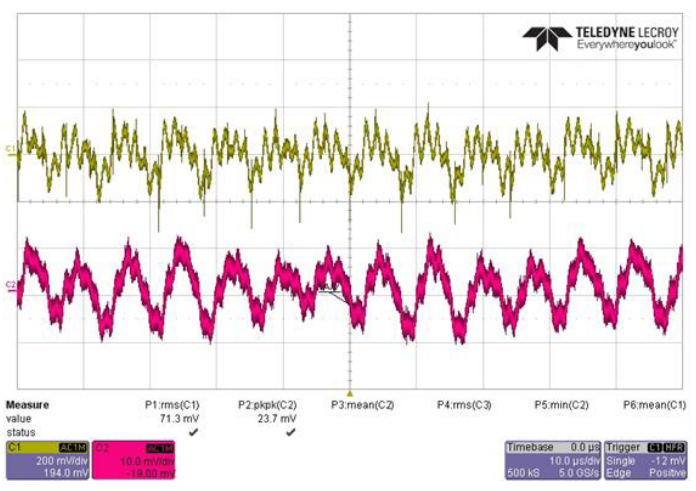

\section{Output Impedance Testing:}

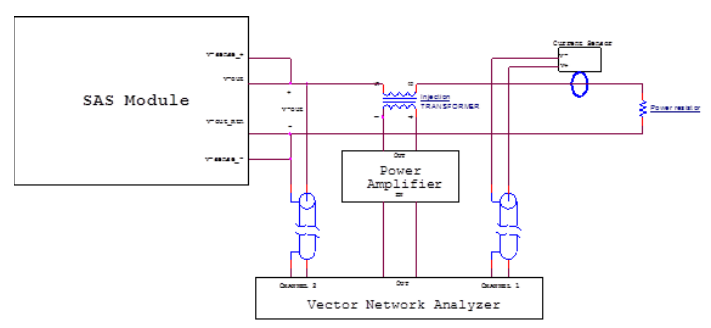

$\mathrm{I} / \mathrm{V}$ curve $44 \mathrm{~V}, 2 \mathrm{~A}, 75.5 \mathrm{~W}$ is loaded and different power resistors are applied to vary the SAS Module dc output. The Injection Transformer is connected in series with the power resistor in order to inject a sinusoidal perturbed voltage signal.

Example of actual impedance performance:

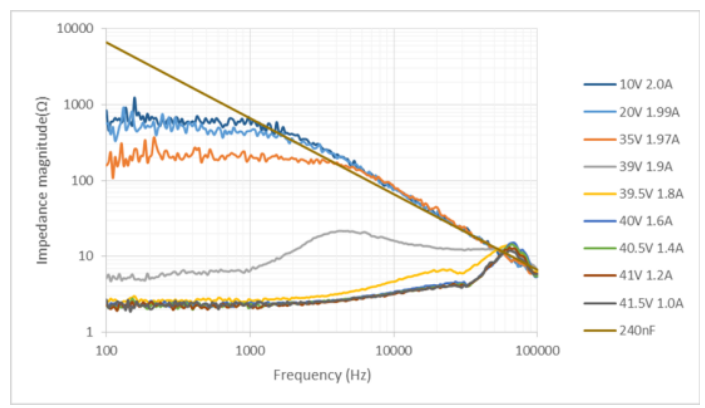

\section{Commercial Evaluation}

Given the early start of the marketing and sales activities for systems based on the RO-5100 SAS Module and stand-alone SAS Modules, a number of contracts, both commercial and institutional in Europe and the USA, have already been captured since 2013 (numbers w/o spares modules):

- Power SCOE with 72x SAS Modules for MPCV-ESM SAW FEE (+option 36x additional units)

- Power SCOE with 36x SAS Modules for MPCV-ESM PCDU EGSE;

- Power SCOE with 48x SAS Modules for Boeing PSTE (+ option 8x 48 additional units);

- Power SCOE with 8x SAS Modules for Lockheed Martin;

- 13x SAS Modules for Solar Orbiter;

- 17x SAS Modules for ExoMars CM;

- 42x SAS Modules for MetOp-SG;

On the basis of the above 236 (plus optional 420) SAS Modules for the period 2015 - 2018 (options until 2020), the commercial "success" is already there and confirms the order of magnitude derived from the above market assessment. 